\title{
ABRUPTIO PLACENTAE- VIGILANCE NEEDED!
}

\author{
Kshama Kedar1, Ashwini Pawar², Surekha Khandale ${ }^{3}$
}

${ }^{1}$ Associate Professor, Department of Obstetrics and Gynaecology, Indira Gandhi Government Medical College, Nagpur.

${ }^{2}$ Resident, Department of Obstetrics and Gynaecology, Indira Gandhi Government Medical College, Nagpur.

${ }^{3}$ Assistant Professor, Department of Obstetrics and Gynaecology, Indira Gandhi Government Medical College, Nagpur.

\section{ABSTRACT}

\section{BACKGROUND}

Antepartum Haemorrhage (APH) is an obstetric emergency, contributing to a significant amount of maternal \& perinatal morbidity and mortality. In Abruptio placentae (Accidental haemorrhage), bleeding occurs due to premature separation of normally situated placenta and it contributes to nearly one third of APH cases. Early evaluation of risk factors to prevent abruption is needed.

The aim of this study is to evaluate how far we have come and the effect of such treatment on the perinatal and maternal outcome.

\section{MATERIALS AND METHODS}

Present study was carried over the period of 2 years at Indira Gandhi Government Medical College, Nagpur. 68 women with gestational age more than 28 weeks of abruptio placenta came during this period. Detailed clinical, sociodemographic and obstetric history was taken and cases managed as per their clinical presentation. Maternal and perinatal complications studied and analysed.

\section{RESULTS}

69.11\% were unbooked and abruption was more in multiparous, and in gestational age of more than 36 weeks (60.29\%). It was associated more with PIH (Pregnancy-induced hypertension) 52.94\%, 21 (30.88\%) cases presented with no foetal heart sound but 14 were of foetal distress. 30 women delivered by caesarean section of which 7 had Couvelaire changes in uterus. Foetal outcome varies with the gestational age, out of 68 women of abruption, only 7 were stillbirths and 7 were early neonatal deaths due to severe prematurity and 1 maternal mortality.

\section{CONCLUSION}

Timely diagnosis and intervention is necessary in APH. PIH is a most common factor which reflects poor antenatal care. It should be made mandatory for all primary health centres to identify high-risk patients at their level and timely referral to tertiary care centres.

\section{KEYWORDS}

Antepartum Haemorrhage (APH), Abruptio Placentae, Accidental Haemorrhage, Couvelaire Uterus, PIH (Pregnancy-Induced Hypertension).

HOW TO CITE THIS ARTICLE: Kedar K, Pawar A, Khandale S. Abruptio placentae- Vigilance needed!. J. Evolution Med. Dent. Sci. 2017;6(88):6094-6098, DOI: 10.14260/jemds/2017/1324

\section{BACKGROUND}

Antepartum haemorrhage (APH) has always been one of the most feared complications in Obstetrics. It's an obstetric emergency, contributing to a significant amount of maternal and perinatal morbidity and mortality in our country. Haemorrhage is one of the leading causes of maternal mortality and morbidity. According to centre for disease control and prevention, haemorrhage was a direct cause of maternal death in about $30 \%$ of cases. APH complicates about $2-5 \%$ of all the pregnancies, ${ }^{1}$ APH can be due to placenta praevia, abruptio placentae, indeterminate cause or local causes of tract. Placenta praevia complicates $0.33 \%$ to $0.55 \%^{2}$ of all pregnancies and incidence of placental abruption is approximately $0.5-1 \% .^{3}$ Abruptio placentae is a condition that occurs due to premature separation of normally situated placenta and it also contributes to nearly one third of cases.

'Financial or Other Competing Interest': None.

Submission 21-09-2017, Peer Review 23-10-2017,

Acceptance 30-10-2017, Published 06-11-2017.

Corresponding Author:

Dr. Kshama Kedar,

Associate Professor,

Department of Obstetrics and Gynaecology,

Indira Gandhi Government Medical College,

Nagpur.

E-mail: kedarkshama@yahoo.com

DOI: $10.14260 /$ jemds $/ 2017 / 1324$
The maternal complications in patients with APH are malpresentation, premature labour, postpartum haemorrhage, sepsis, \& shock. Various foetal complications are premature baby, low birth weight, intrauterine death, congenital malformation and birth asphyxia. Maternal mortality due to APH has significantly decreased in developed countries to about $6 / 1,00,000$ live births due to better obstetrical outcome. In India, maternal mortality is still very high and is 4.08/1000 live births. ${ }^{4}$ In developing countries, widespread pre-existing anaemia, difficulties with transport, restricted medical facility, decreased awareness on part of patient and relatives are largely responsible for high MMR. Perinatal mortality is less than 10 per 1000 total births in developed countries while it is much higher in India i.e. 60/1000 total births. ${ }^{4}$ Although APH cannot be prevented, maternal and perinatal morbidity and mortality associated with APH can be reduced significantly by aggressive expectant management. Presently, increasing use of TAS/TVS for placental localisation and to diagnose abruptio placentae, improved obstetrical and anaesthetic facilities, increasing use of blood and its products to correct anaemia and advanced neonatal care facilities to make increased chances of survival of a preterm infant, all collectively have played important role in decreasing perinatal as well as maternal morbidity and mortality. ${ }^{5}$ Obstetricians have struggled hard to reduce the devastation so that the end results would be happy for APH during pregnancy with timely and aggressive treatment, which 
will go a long way in further reducing the maternal and foetal morbidity and mortality. This study is to evaluate how far we have come and the effect of such treatment on the perinatal and maternal outcome.

\section{Aim}

To study the causes and maternal and foetal outcome in abruptio placentae, and also to assess the importance of early diagnosis and treatment.

\section{Objectives}

To emphasise the importance of early diagnosis and prompt treatment in the improvement of maternal and perinatal outcome. Also, to determine the causes of abruptio placentae and to assess the value of current obstetric practice in managing abruptio placentae over a period of 2 years.

\section{MATERIALS AND METHODS}

\section{Study Design}

It was an observational study carried out at Indira Gandhi Government Medical College, Nagpur which is a tertiary care centre in central India getting referrals from nearby states, district, sub-district and rural hospitals.

\section{Sample Size \& Participants}

Study was carried over the period of 2 years from December 2013 to November 2015 after approval of institutional ethical committee. A total 68 women of abruptio placentae who came during this period in emergency or routine OPD, who consented to be a part of research were included.

\section{Inclusion \& Exclusion Criteria}

All women of abruptio placentae more than period of 28 weeks were included and of less than 28 weeks were excluded. Placenta praevia and unclassified haemorrhage were excluded along with women suffering from any bleeding disorders and bleeding from a source other than uterus.

\section{Methodology}

All cases coming to labour room from December 2015 to November 2016 were studied. Patients of accidental haemorrhage included and patients of placenta praevia and history of bleeding from any other causes excluded. In all patients coming to labour room with complaints of bleeding per vaginum, quick history taken and physical examination done. Information regarding sociodemographic factors and dietary habits were noted. Special enquiry was made, regarding smoking and drug use, history regarding previous antenatal checkups, the kind of antenatal care received and the number of antenatal visits was noted. From her antenatal record, any previous high recording of blood pressure, presence of albuminuria and haemoglobin levels were noted.

History was taken in detail, so as to ascertain the amount and character of bleeding, any initiating factors such as trauma or coitus, a history of ruptured membranes or previous vaginal bleeding, association of abdominal pain or labour pains; duration between time of onset of bleeding and arrival at the hospital noted. History was taken regarding the number of previous pregnancies and their outcome, number of live issues, complication during previous pregnancies, mode of delivery and complications during and after deliveries. Any previous history of APH was specifically enquired for. History of previous caesarean section (CS), hysterotomy was taken.
History of bleeding and time of admission and distance traversed to get admitted to the hospital, information regarding any $1^{\text {st }}$ and $2^{\text {nd }}$ trimester complications like bleeding or spotting was taken.

\section{General Physical Examination}

It was done meticulously to assess both maternal and foetal condition. Maternal examination included maternal pulse, blood pressure, respiratory rate, clinical evidence of shock, cyanosis and pedal oedema.

\section{Abdominal Examination Included}

Symphysio-fundal height, to ascertain whether the uterine fundus was compatible with the estimated gestational age, the presence of uterine tenderness and uterine contractions, the number of foetus and viability, the presentation and engagement of presenting part. Foetal heart sound was auscultated for rate, rhythm and tone.

\section{Management}

All patients presenting with abruptio placenta were initially investigated and managed as outlined below, but subsequent management was determined according to the suspected cause, severity and type of bleeding and the gestational age of the pregnancy. The initial management included intravenous line with a wide bore cannula inserted and intravenous fluids given according to the need. Blood samples were obtained from the patient for immediate haemoglobin and haematocrit estimation, complete blood count and for grouping and cross matching and sent to laboratory. Bleeding time, clotting time and clot retraction time were done at bedside. Ultrasound scan was done to establish the cause of APH, when maternal and foetal conditions were stable. Presence and degree of placenta praevia and placental separation were looked for specifically.

\section{After this Initial Management, Further Management was Based on the following Criteria-}

1. The bleeding had stopped.

2. The bleeding was continuing but remained mild and nonlife threatening.

3. The bleeding was continuing and was severe and life threatening.

4. The foetus was in distress, irrespective of the bleeding pattern.

5. Intrauterine death.

\section{Abruptio Placentae}

Once a probable diagnosis of AP was made, management depended on the severity, associated complications, the state of the mother and the foetus, gestational age and whether the patient was in labour or not-

1. Immediate delivery:

a. If the patient was found to have gone into labour, labour was accelerated by doing amniotomy followed by oxytocin drip. If delivery was not imminent or within 6 hours, patient was taken for CS. Labour was monitored carefully with strict watch on foetal heart sound, progress of labour, maternal vitals, abdominal girth/fundal height charting, bedside coagulation profile and intake output charting was done.

b. If the patient was not in labour and was with pregnancy of 37 weeks or more, induction of labour 
was done by rupture of membrane with or without oxytocin.

2. Caesarean section was done for
a. Unfavourable cervix.
b. Other associated obstetrical conditions which in themselves were indications for CS.
c. ARM failed to control bleeding.
d. There was appearance of foetal distress.

\begin{tabular}{|c|c|c|c|c|c|c|c|}
\hline $\begin{array}{c}\text { Type of } \\
\text { APH }\end{array}$ & $\begin{array}{c}\text { P0 } \\
\mathbf{( \% )}\end{array}$ & $\begin{array}{c}\text { P1 } \\
\mathbf{( \% )}\end{array}$ & $\begin{array}{c}\text { P2 } \\
\mathbf{( \% )}\end{array}$ & $\begin{array}{c}\text { P3 } \\
\mathbf{( \% )}\end{array}$ & $\begin{array}{c}\text { P4 } \\
\mathbf{( \% )}\end{array}$ & $\begin{array}{c}\text { P5 } \\
\mathbf{( \% )}\end{array}$ & $\begin{array}{c}\text { T0TA } \\
\mathbf{L}\end{array}$ \\
\hline $\begin{array}{c}\text { Abruptio } \\
\text { placentae }\end{array}$ & 15 & 28 & 14 & 7 & 1 & 3 & 68 \\
$(22.05)$ & $(41.17)$ & $(20.58)$ & $(10.29)$ & $(1.47)$ & $(4.41)$ & $(100)$ \\
\hline
\end{tabular}

Table 1. Distribution of Patients According to Parity

Abruptio placentae was more common in multipara than in nullipara.

\begin{tabular}{|c|c|c|c|c|c|}
\hline Type of APH & $\begin{array}{c}<\mathbf{2 8} \\
(\mathbf{\%})\end{array}$ & $\begin{array}{c}\mathbf{2 9 - 3 2} \\
(\mathbf{\%})\end{array}$ & $\begin{array}{c}\mathbf{3 3 - 3 6} \\
\mathbf{( \% )}\end{array}$ & $\begin{array}{c}>\mathbf{3 6} \\
(\mathbf{\%})\end{array}$ & Total \\
\hline Abruptio & 1 & 7 & 19 & 41 & 68 \\
placentae & $(1.47)$ & $(10.29)$ & $(27.94)$ & $(60.29)$ & $(100)$ \\
\hline \multicolumn{2}{|c|}{ Table 2. Gestational Age at Time of Admission (Weeks) } \\
\hline
\end{tabular}

Maximum patients of Abruptio placentae more than 36 weeks. (60.29\%).

\begin{tabular}{|c|c|c|c|c|}
\hline $\begin{array}{c}\text { Type of } \\
\text { APH }\end{array}$ & $\begin{array}{c}\text { Absent } \\
\text { (\%) }\end{array}$ & $\begin{array}{c}\text { Positive } \\
\text { (\%) }\end{array}$ & $\begin{array}{c}\text { Foetal } \\
\text { Distress (\%) }\end{array}$ & Total \\
\hline $\begin{array}{c}\text { Abruptio } \\
\text { placentae }\end{array}$ & $21(30.88)$ & $33(48.52 \%)$ & $14(20.58)$ & $68(100)$ \\
\hline \multicolumn{4}{|c|}{ Table 3. According To Foetal Heart Sound } \\
\hline
\end{tabular}

21 cases of abruptio placentae had absent foetal heart sounds (30.88\%), 14 (20.58\%) had foetal distress and 33 $(48.52 \%)$ had foetal heart sounds.

\begin{tabular}{|c|c|}
\hline Associated Factors & Abruptio Placentae (\%) \\
\hline Nil & $7(10.29)$ \\
\hline Anaemia & $16(23.51)$ \\
\hline $\mathrm{PIH}$ & $36(52.94)$ \\
\hline Previous D\&C & $2(2.94)$ \\
\hline Previous LSCS & $5(7.35)$ \\
\hline PROM & $2(2.94)$ \\
\hline Total & $68(100)$ \\
\hline \multicolumn{2}{|c|}{ Table 4. Associated Factors } \\
\hline
\end{tabular}

36 cases $(52.94 \%)$ had PIH as associated factor followed by anaemia in $16(23.51 \%)$ cases.

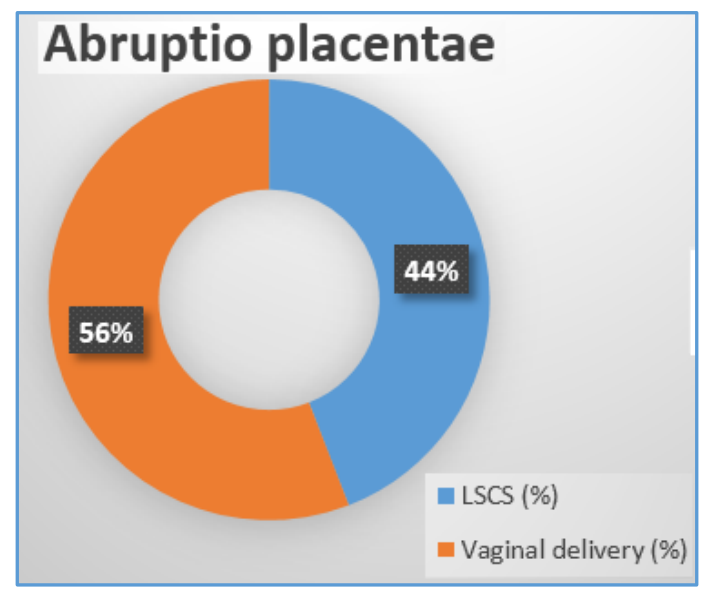

Chart 1. Showing Mode of Delivery
$30(44.11 \%)$ patients from abruptio placentae underwent caesarean section and 38 (55.88\%) underwent vaginal delivery. This was found to be significant. ( $p$ value 0.0001 , Chi square test).

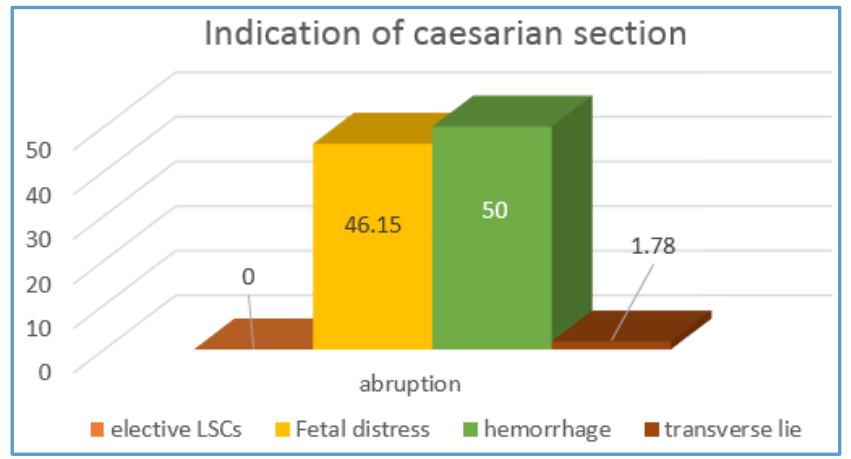

Chart 2. Showing Indications of Caesarean Section

The commonest indication for caesarean section in abruption was haemorrhage in 13 cases $(50 \%)$ followed by foetal distress in 12 cases (46.15\%) in abruptio placentae. All caesarean sections were done in emergency.

\begin{tabular}{|c|c|}
\hline Maternal Outcome & Abruptio Placentae \\
\hline Nil & $5(7.35)$ \\
\hline Anaemia & $29(42.64)$ \\
\hline Couvelaire & $7(10.29)$ \\
\hline Caesarean Section, Hysterectomy & $0(0)$ \\
\hline PPH & $25(36.76)$ \\
\hline Renal Failure & $1(1.47)$ \\
\hline Scar Dehiscence & $0(0)$ \\
\hline Sepsis & $0(0)$ \\
\hline UTI & $1(1.47)$ \\
\hline Total & $\mathbf{6 8 ( 1 0 0 )}$ \\
\hline Table 5. Maternal Outcome \\
\hline
\end{tabular}

$46.78 \%$ patients of abruptio placentae had anaemia. In case of abruptio placentae, $36.76 \%$ patients had postpartum haemorrhage. 7 cases (10.29\%) had Couvelaire uterus. One patient died because of renal failure.

\begin{tabular}{|c|c|}
\hline Morbidity & Abruptio Placentae \\
\hline Normal & $22(32.35 \%)$ \\
\hline Stillbirth and neonatal death & $14(20.58 \%)$ \\
\hline Low birth weight & $46(67.74 \%)$ \\
\hline Prematurity & $6(8.82 \%)$ \\
\hline Total & 68 \\
\hline
\end{tabular}

Low birth weight in $46(67.74 \%)$ cases was the commonest outcome in abruptio placentae followed by stillbirths and neonatal death in 14 (20.58\%) cases.

\section{DISCUSSION}

In our study, we studied 68 women with abruptio placentae, out of which maximum 47 (69.11\%) were unbooked. Our study shows that $69.11 \%$ cases were unbooked, Rai et al (1987) also reported more number of abruptio placentae cases were unbooked in his study. ${ }^{6}$ The importance of antenatal visits in prevention of abruptio placentae has also been stated by Baskette et al (1977) who reported that in their series $3 / 4^{\text {th }}(75 \%)$ of cases were unbooked. ${ }^{7}$ 
Increasing age has been implicated as a predisposing factor to both Placenta praevia and Abruptio placentae. Mean age of abruptio placentae patient was 30-35 years. The present study showed an increased incidence of abruptio placentae from below 24 years to after 24 years. Incidence of abruptio placentae was found to increase from $19.11 \%$ (age group 2024 years) to $32.35 \%$ (age group 30-34 years). Paul Pedowitz $(1965)^{8}$ and B Das $(1975)^{9}$ have also reported maximum number of cases in the same age group. William et al (1991) ${ }^{10}$ also reported increased risk of abruptio placentae with advancing age.

In the present study, it was observed that the incidence of accidental haemorrhage was more common in multipara than in nullipara and the mean parity was 1. $6 \pm 1.3$. (Table 4). Ananth et al (1996) ${ }^{11}$ showed that risk of placental abruption increased with high parity and Vaidya et al (1984) ${ }^{12}$ observed that only $14 \%$ patients of abruptio placentae were primiparas.

\section{Period of Gestation at the Time of Admission (Weeks) (Table 2)}

In Abruptio placentae group, 41 patients (60.29\%) had a period of gestation more than 36 weeks at the time of admission.

\section{FHS at the Time of Admission- Table 3}

In 33 cases $(45 \%)$ of abruptio placentae, FHS was normal, 21 cases (30.88\%) had absent FHS and 14 cases $(20.58 \%)$ had evidence of foetal distress at admission. The results of our study are similar to that of Chakraborty et al (1993). ${ }^{13}$ In their study, evidence of foetal distress was present in $26.08 \%$ patients with Abruptio placentae. ${ }^{14}$

\section{Factors Predisposing to APH - Table 4, Previous LSCS}

In the present study, $5(7.35 \%)$ cases of antepartum haemorrhage had a history of previous LSCS.

\section{Previous D \& C}

The present study showed 2 cases of Abruptio placentae had a history of previous abortion. Hibbard et al (1966) ${ }^{15}$ reported an increased incidence of Abruptio placentae in women with $\mathrm{h} / \mathrm{o}$ of previous abortion.

\section{PROM}

Incidence of PROM was found to be in 2 cases of abruptio placentae patients in this study (Statistically nonsignificant). Major and colleagues $(1995)^{16}$ reported an increased incidence of Abruptio placentae increases PROM.

\section{Hypertensive Disorders of Pregnancy}

In the present study, 36 patients (52.94\%) with abruptio placentae had hypertensive disorders of pregnancy. Hibbard et al (1966) ${ }^{15}$ found incidence of hypertensive disorders of pregnancy was $7.4 \%$ in antepartum haemorrhage patient. Rai et al (1987) ${ }^{6}$ found $4.4 \%$ incidence of hypertensive disorders of pregnancy in Antepartum haemorrhage patients.

\section{Mode of Delivery}

(Chart 1) Of all the patients of Abruptio placentae, 38 cases (55.88\%) delivered vaginally and 30 cases $(44.11 \%)$ delivered by Caesarean section. All obstetricians agree that early and ${ }^{17}$ timely Caesarean section improve perinatal salvage in patients with abruptio placentae.
In present study, commonest indication of caesarean section (Chart 2) was haemorrhage in abruptio placentae (13 cases) followed by foetal distress (12 cases), malpresentation ( 1 case). Cotton et al (1980) ${ }^{18}$ reported haemorrhage as an indication for caesarean section in $70.6 \%$ of patients of Antepartum haemorrhage in their study.

\section{Maternal Outcome}

One of the major aims of proper management of APH cases is to minimise the maternal mortality and morbidity. Anaemia was most common complication of APH found in 29 patients of abruptio placentae.

Postpartum haemorrhage was the $2^{\text {nd }}$ most common complication in Antepartum haemorrhage patients and was seen in 25 patients of abruptio placentae. Postpartum haemorrhage seen in 36 cases of Abruptio placentae. In a study by Hurd et al,19 (1983) $13.3 \%$ cases of APH had PPH. Chakraborty et al (1993) 15 reported an incidence of $16.25 \%$ $\mathrm{PPH}$ in cases of antepartum haemorrhage. In abruption placenta group, Couvelaire uterus was seen in 2 (3.6\%) cases. Rai et al $(1981)^{6}$ reported Couvelaire uterus in $10.5 \%$ of Antepartum haemorrhage patients in their study. One maternal death occurred in present study giving a maternal mortality of 1 in Antepartum haemorrhage patients. The patient had grade III Abruption placenta and died due to renal failure. Gorodeski et al (1981) ${ }^{20}$ reported maternal mortality of $0.46 \%$ in antepartum haemorrhage while Pedowitz (1965) ${ }^{8}$ reported it as $0.9 \%$. Cotton et al (1980) ${ }^{18}$ found no mortality in cases of Placenta praevia in their series. Results of our study are similar to those of Pedowitz study.

\section{Neonatal Outcome and Complication}

Prematurity was commonest in abruptio placentae. 6 neonates had prematurity. Out of 68 babies, 46 babies of abruptio placentae were with low birth weight. There are 7 early neonatal deaths and 7 stillbirths in abruptio placentae.

\section{Summary}

Maximum cases were unbooked (69.11\%) and it was more common in multiparous than in nulliparous. Abruption was more common in age group of more than 36 years of age. At the time of admission, 41 cases $(60.29 \%)$ were more than 36 weeks of gestation. It was associated more with pregnancyinduced hypertension (52.94\%), most of the patients presented with no foetal heart sounds, i.e. 21 cases $(30.88 \%)$, but 14 cases were of foetal distress. Most of them were delivered by caesarean section (30 cases) and out of 30 cases 7 had Couvelaire changes in uterus.

Only one mortality was present in this group due to renal failure. Abruptio placentae comprises largest group of perinatal mortality cases (14). Prematurity was seen in 6 cases.

\section{CONCLUSION}

From the present study, it is concluded that antepartum haemorrhage is still a leading cause of maternal morbidity. Though maternal morbidity reduced with modern management of antepartum haemorrhage, but timely diagnosis and intervention is necessary. Most of the patients were unbooked (69.11\%) and multiparous which suggests their careless attitude towards pregnancy and not taking antenatal care. Pregnancy-induced Hypertension is the most 
common cause of abruptio placentae $(52.94 \%)$ which reflects poor antenatal care. It should be made mandatory for all primary health centres to identify such high-risk patient at their level and timely referral to tertiary care centres. Foetal outcome varies with the gestational age, out of 68 women of abruption, only 7 were stillbirths and 7 were early neonatal deaths due to severe prematurity. "A Stitch in Time Saves Nine."

Routine antenatal check-up, timely referral, timely caesarean section, liberal blood transfusion, correction of anaemia and wider acceptance of expectant line of management in a tertiary centre with availability of blood transfusion and good neonatal intensive care unit will help further to lower the perinatal and maternal morbidity and mortality.

\section{REFERENCES}

[1] Frederiksen MC, Glassenberg R, Stika CS. Placenta previa: a 22-year analysis. Am J Obstetrics and Gynecology 1999;180(6 Pt 1):1432-7.

[2] Crane JMG, van den Hof MC, Dodds L, et al. Neonatal outcomes with placenta previa. Obstetrics and Gynecology 1999;93(4):541-4.

[3] Ananth CV, Smulian JC, Vintzileos AM. Incidence of placental abruption in relation to cigarette smoking and hypertensive disorders during pregnancy: a metaanalysis of observational studies. Obstetrics \& Gynecology 1999;93(4):622-8.

[4] Park. Maternal and child health. Park's textbook of preventive and social medicine. $17^{\text {th }}$ edn. Jabalpur: Banarasi Das Bhanot 2000.

[5] Dutta DC. Antepartum haemorrhage. In: Konar H. edr. Textbook of obstetrics. $6^{\text {th }}$ edn. Calcutta: New Central Book Agency 2004:243-61.

[6] Rai L, Duvvi H, Rao UR, et al. Severe abruptio placentae-still unpreventable. Int J Gynecology \& Obstetrics 1989;29(2):117-20.

[7] Baskette TF. Grand multiparity - a continuing threat: a 6-year review. Can Med Assoc J 1977;116(9):1001-4.
[8] Pedowitz P. Placenata previa. An evaluation of expectant management and the factors responsible for fetal wastage. An J Obstet \& Gynecol 1965;93:16-25.

[9] Das B. Antepartum haemorrhage in three decades. J Obstetrics \& Gynecology India 1975;25:636-7.

[10] William MA, Mittendorf R. Increasing maternal age as a determinant for placenta previa. More important than increasing parity? J Report Med 1993;38(6):425-8.

[11] Ananth CV, Wilcox AJ, Savitz DA, et al. Effect of maternal age and parity on the risk of uteroplacental bleeding disorders in pregnancy. Obstet \& Gynecology 1996;88(4 Pt 1):511-6.

[12] Vaidya PR. Abruptio placentae: a study of 105 cases. J Obstetrics \& Gynecology 1984:34.

[13] Chakraborty B, De KC. Evaluation of third trimester bleeding with reference to maternal and perinatal outcome. J Obstetrics \& Gynecology India 1993;42: 166-71.

[14] Eskes TK. Homocysteine and human reproduction. Clin Exp Obstetrics \& Gynecology 2000;27(3-4):157-67.

[15] Hibbard BM, Jeffcoate TNA. Abruptio Placentae. Obstetrics \& Gynecology 1966;27(2):155-67.

[16] Major CA, de Veciana M, Lewis DF, et al. Preterm premature rupture of membranes and abruptio placentae: is there an association between these pregnancy complications? Am J Obstetrics \& Gynecology 1995;172(2 Pt 1):672-6.

[17] Kayani SI, Walkinshaw SA, Preston C. Pregnancy outcome in severe placental abruption. $\mathrm{Br} \mathrm{J}$ Obstetrics \& Gynaecology 2003;110(7):679-83.

[18] Cotton DB, Read JA, Paul RH, et al. The conservative aggressive management of placenta previa. Am J Obstetrics \& Gynecology 1980;137(6):687-95.

[19] Hurd WW, Miodovnik M, Hertzberg V, et al. Selective management of abruptio placentae: a prospective study. Obstetrics \& Gynecology 1983;61(4):467-73.

[20] Gorodeski IG, Bahari CM, Schachter A, et al. Recurrent placenta previa. Eur J Obstetrics \& Gynecology Reprod Biol 1981;12(1):7-11. 